\title{
La diplomacia indígena: un enfoque transdiplomático*
}

\author{
Indigenous diplomacy: a transdiplomatic approach
}

\author{
Gabriel Andrés Arévalo Robles** \\ Universidad Antonio Nariño, Bogotá, Colombia
}

Recibido: 9 de Abril de 2017 Aprobado: 19 de Mayo de 2017

\begin{abstract}
Resumen
El presente trabajo pretende discutir el relato diplomático ancestral desde el particular ángulo de la transdiplomacia. Con este objetivo, presentará aspectos históricos de la diplomacia indígena a lo largo de la historia del sistema mundial, concentrando los esfuerzos finales en la emergencia diplomática indígena contemporánea de finales del siglo XX y principios del siglo XXI. Navegando la práctica diplomática indígena, debatirá las nociones de la diplomacia occidental, demostrando que la idea de diplomacia es mucho más amplia y crítica que las usadas por los clásicos enfoques, y relevante para las luchas contemporáneas contrahegemónicas de la globalización.
\end{abstract}

Palabras clave: diplomacia, cabildeo, resistencia.

\begin{abstract}
The present work intends to discuss ancestral diplomatics from the particular angle of the transdiplomacy. To this end, it will present historical aspects of indigenous diplomacy

Artículo resultado de Tesis Doctoral "La emergencia de la diplomacia indígena contemporánea: dimensiones políticas y simbólico/funcionales. Una mirada desde Latinoamérica/Abya-Yala” (2016). Universidad del País Vasco/Euskal Herriko Unibertsitatea. Financiada por la Beca Predoctoral del Gobierno Vasco.

* PhD. en Estudios Internacionales de la Universidad del País Vasco/Euskal Herriko Unibertsitatea. Master de Estudios Internacionales de la (UPV/EHU). Abogado, sociólogo. Actualmente es el Director de la Unidad para el Desarrollo de la Ciencia y la Investigación -UDCI- de la Facultad de Derecho de la Universidad Antonio Nariño, Sede Duitama.
\end{abstract}


throughout the history of the world system, concentrating the final efforts on the contemporary indigenous diplomatic emergency of the late twentieth and early twentyfirst century. Navigating indigenous diplomatic practice, it will discuss the notions of Western diplomacy by demonstrating that the idea of diplomacy is much broader and more critical than those used by classical approaches and relevant to the contemporary counterhegemonic struggles of globalization.

Keywords: diplomacy, lobbying, resistance.

Debemos estar orgullosos de ser indios, que nos llamen indios; con la palabra indio nos conquistaron, con la palabra indio hoy nos liberaremos.

Fausto Reinaga (1971, p. 89)

La diplomacia indígena es el conjunto de actividades... para hacer incidencia ante nuestros pueblos, para sensibilizar a la sociedad civil, para garantizar el respeto de nuestros derechos según nuestros planes de vida y la ley de Origen. Significa ir a espacios externos con dedicación, responsabilidad, sabiduría y principios. Hay que comunicarse con la fuerza y el poder de los ancestros. Hay que dejar un buen ambiente y un buen espíritu. Llevar a palabra al mundo no-indígena significa entender los procesos del mundo occidental, bien sea de los gobiernos o de organismos internacionales y multilaterales.

Significa estrechar relaciones para tejer alianzas, conformar redes, estar en contacto permanente con otros que apoyan la lucha indígena de resistencia y pervivencia en el territorio.

Ana Manuela Ochoa Arias, Joanne Hutchinson y Luis Fernando Arias Arias (2012, p. 11)

La diplomacia unificada desde la diversidad busca fortalecer la capacidad de incidencia de los pueblos indígenas, que a su vez genera credibilidad, apoyo y solidaridad en el plano nacional e internacional... es de gran relevancia entre nosotros los indígenas generar lazos conjuntos, para que el tejido sea más fuerte a la hora de dar a conocer nuestro pensamiento y levantar nuestra voz.

Miguel Palacín (2007, p. 1)

142 Si Somos Americanos. Revista de Estudios Transfronterizos 


\section{Ilustración 1}

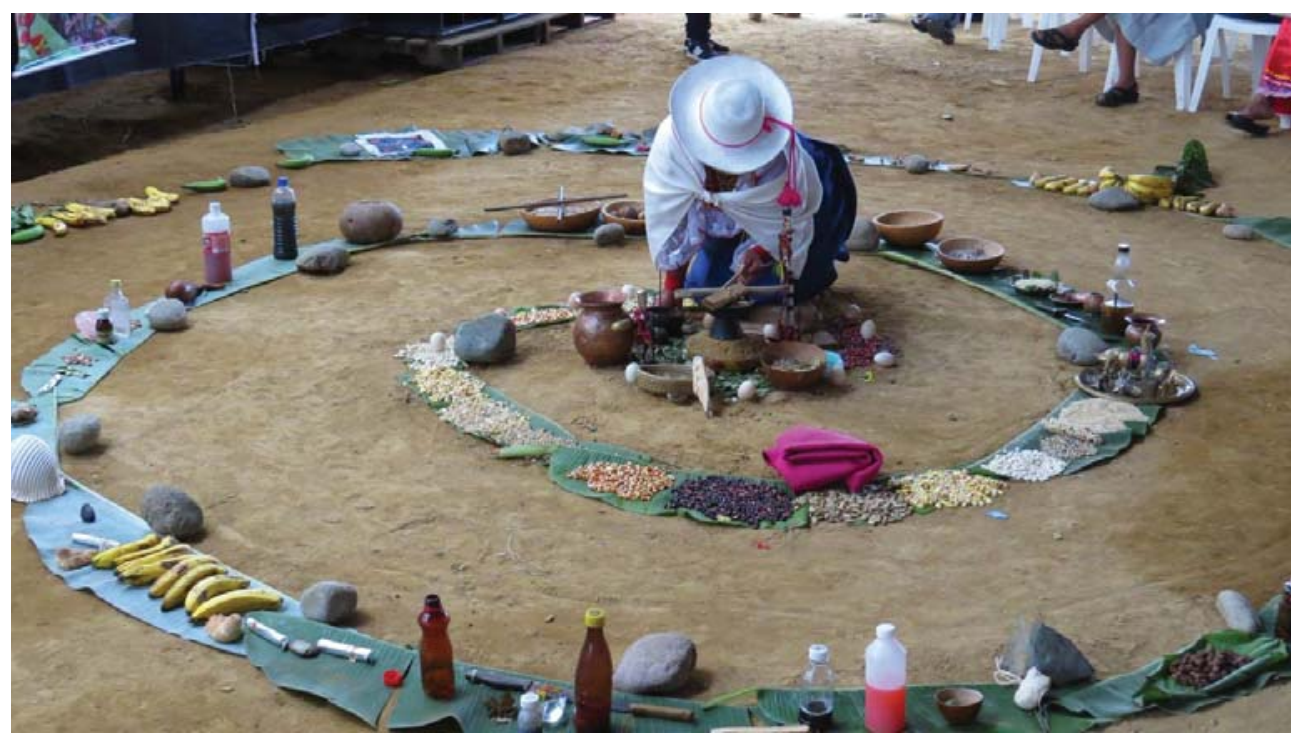

Ritual de Armonización y Encendido del Fuego Sagrado, V Cumbre Continental de Pueblos Indígenas del Abya Yala, Resguardo Indígena de la María, Cauca, Colombia, 2013. Fotografía: Gabriel Andrés Arévalo.

\section{Introducción}

La diplomacia indígena -como unidad cognitiva de significado- está conformada por la unión de dos palabras históricamente limitadas al mundo occidental, aunque transformadas críticamente y reapropiadas en clave reivindicativa. El uso reapropiado políticamente de indígena o indio para enunciar la subjetividad histórica de lucha contra el colonialismo e imperialismo es más conocido que la noción de diplomacia, usada con un restringido número de significados que recorta la alteridad histórica mundial. Es común asociar la historia de la diplomacia a las embajadas, la profesión, la técnica y el protocolo de los Estados occidentales. Dicha conexión está asociada a la producción teórica de las relaciones internacionales y la diplomacia, dominada por académicos norteamericanos, europeos y -en menor medida-australianos, preocupados por temáticas que atañen a los actores hegemónicos de la economía global (Jones, 2006) y que oculta fenómenos históricos transfronterizos que involucran actores, interacciones y significados periféricos excluidos 
del relato histórico diplomático, pero que fueron determinantes en la formación y desarrollo del sistema mundial.

Aunque no es principal objetivo de este artículo desarrollar el debate sobre la limitada concepción de la diplomacia, es necesario presentar -brevemente- la postura teóricometodológica que reconstruye la historia de la diplomacia indígena. Para ello es usada la noción de transdiplomacia, concebida como una herramienta teórica-metodológica que busca investigar fenómenos diplomáticos desde una perspectiva holística, dinámica, flexible, abierta, crítica, provocativa e hipotética de la historia ${ }^{1}$. El enfoque de la transdiplomacia es un enfoque para analizar y comprender la interacción diplomática de pueblos, naciones, comunidades, grupos y entidades individuales que han dado forma al sistema mundial y que han sido ignorados, invisibilizados y/o marginados por un marcado eurocentrismo teórico-político de la disciplina.

La transdiplomacia, como veremos adelante, rivaliza con el relato eurocéntrico que ha dado forma a la historia de la diplomacia, y para ello sugiere una transgresión subversiva ${ }^{2}$ de la "historia universal" de la relaciones internacionales. La palabra diplomacia no debería ser exclusiva de una actividad estatal, sino una práctica humana y transhistórica de alteridad, que acontece cuando entidades diferentes se encuentran y buscan gestionar la diferencia por medio de normas y procedimientos constantes o ad hoc.

La transdiplomacia usa el "trans" para evocar las cosmovisiones, conocimientos, experiencias y prácticas diplomáticas que perviven en la exterioridad relativa del sistema mundial ${ }^{3}$, recordando que los procesos de colonización, neocolonización e imperialismo

\footnotetext{
Transdiplomacia es una plataforma teórico-metodológica que cuestiona el eurocentrismo diplomático, sintiéndose en buena parte ajena a las teorías clásicas de la diplomacia y las relaciones internacionales por su incapacidad para explicar fenómenos que escapan a su tradición intelectual. A partir de esta deficiencia, la transdiplomacia elabora una plataforma de análisis e interpretación tomando un conjunto diverso de teorías y trabajos producidos dentro y fuera del campo diplomático, producidos desde la experiencia latinoamericana (Abya Yala-Cóndor), norteamericana (Abya Yala-Águila) y del enfoque diplomático "posmoderno". Dicho enfoque fue creado en la tesis doctoral "La emergencia de la diplomacia indígena contemporánea: dimensiones funcionales y simbólico/culturales. Una mirada desde Latinoamérica/Abya-Yala”, realizada por Gabriel Andrés Arévalo Robles. Universidad del País Vasco/Euskal Herriko Unibertsitatea. Bilbao, invierno de 2016.

2 Dicha transgresión responde a la ilusión de alterar el orden y destruir la estabilidad que está sujetada por candados teóricos que impiden usar nuestra imaginación política e intelectual. Me parece importante que, sin desconocer el conjunto de teorías dominantes, construyamos herramientas teóricas desde nuestros lugares enunciativos más útiles para interpretar nuestra realidad y enfrentar los retos que supone nuestra interacción con el mundo global.

3 Exterioridad es en el pensamiento de Enrique Dussel "alteridad". Esta idea es tomada de Emmanuel Levinas, donde la exterioridad no se define por oposición a la interioridad, sino como un cara-a-cara, una irreductibi-
}

\section{Si Somos Americanos. Revista de Estudios Transfronterizos}


no lograron exterminar o eliminar otras formas de gestionar la alteridad y vencer el extrañamiento "original" de quienes se vieron invadidos y dominados. En ese sentido, la transdiplomacia no pretende ser solamente un enfoque descriptivo de "novedosos fenómenos" diplomáticos. Piensa el estudio diplomático como provechoso para aportar a los procesos de resistencia "desde abajo".

Aunque el término "diplomacia" es una arbitrariedad epistémica-disciplinar construida dentro de un relato hegemónico, es empleada como una reapropiación creativa en clave de equivalente homeomórfico (Panikkar, 1994). Es usada como una herramienta de correspondencias entre fenómenos que suceden en diferentes culturas y espacio-tiempos, pero sin hacer simplemente un uso analógico. No se trata de adecuar las múltiples expresiones de la diplomacia con los contenidos y formas de la diplomacia estatal; cada una tiene sus especificidades. La diplomacia, como se entiende aquí, resulta funcional para develar el ocultamiento del relato diplomático eurocéntrico, así como para mostrar la reapropiación y reinterpretación que hacen otros actores para enfrentar las relaciones de poder en las que se ven imbuidos.

Tiene una dimensión "utópica" sobre el sentido ontológico y axiológico de las interacciones humanas, que anima tanto los procesos de investigación como la práctica diplomática. Privilegia el encuentro diplomático para enfrentar los conflictos, las tensiones y las ambigüedades sobre las que se desarrolla el sistema mundial, pero sobre todo invoca un nuevo sentido de convivencia por medio de un espacio de negociación que reconoce, confronta y transforma las relaciones de desigualdad, sean económicas o políticas. Por su sentido utópico-crítico, la transdiplomacia no pretende mejorar la comprensión del sistema diplomático oficial, sino subvertirlo, transformarlo, convertirlo en la posibilidad constituyente de un proyecto planetario más allá de la civilización occidental.

Basados en la amplia noción de transdiplomacia, podemos afirmar que la diplomacia indígena es a la vez un campo semántico de discusión sobre el entendimiento diplomático y una práctica de mediación de la diferencia basada en la identidad étnica, en la que en cada tiempo y lugar, individuos, líderes y representantes han entablado tratos inmediatos

lidad frente al pensamiento totalizador fundado en lo mismo. La exterioridad contiene la otredad (múltiple, dinámica) en clave de resistencia a la homogenización, la totalización o la reducción de lo múltiple; exterioridad que es planteada en términos de conflictiva alteridad y que podría verse en términos de lo absoluto o lo relativo. Ramón Grosfoguel toma esta idea de Dussel y la desarrolla diciendo que la exterioridad tiene la característica de ser relativa en la medida que "todos hemos sido salpicados por la colonialidad", es decir, que dichas culturas que han vivido el rigor de la modernidad tienen un lado que ha sido colonizado, pero con una exterioridad latente que constituye las fuerzas transmodernas. 
o relaciones estables con entidades sociales y políticas para tratar asuntos de diferente índole, en el marco de un conjunto de reglas, normas y procedimientos que han permitido -no sin problemas, tensiones y conflictos- la interlocución y la comunicación. En lo concerniente a nuestro propósito, pretendemos ofrecer los rasgos principales de la diplomacia indígena en términos históricos y finalmente presentar las características de su expresión emergente en las últimas décadas del siglo XX y principios del siglo XXI.

\section{Diplomacia indígena y transdiplomacia: una versión histórica}

Mientras la diplomacia moderna del sistema mundial nace en el Atlántico del siglo XV con la interacción entre invasores y pueblos ancestrales, la diplomacia indígena es un viejo fenómeno que antecede a la conquista de América-Abya Yala ${ }^{4}$ Los pueblos indios habían interactuado históricamente a través de procesos de ancestral diplomacia, creando vínculos formales, informales e interpersonales a través de las fronteras de la comunidad, el idioma, la normatividad social y las prácticas culturales, conformando y estableciendo permanentes sistemas de comunicación e intercambio diplomático. Así lo afirma Jeff Corntassel (2007) al decir: "Indigenous nations practiced diplomacy long before first contact with colonial powers by sending delegations to global destinations in order to foster new alliances of peace and friendship" (p. 142). Pero a partir de 1492, la diplomacia indígena ancestral y la medieval entraron en progresiva transformación tras el contacto transoceánico, tal como lo recuerda Gustavo Torres (2013):

La diplomacia indígena hunde sus raíces en los largos y penosos procesos de colonización acontecidos en distintas regiones del mundo a partir del siglo XVI, con la colonización, principalmente por las culturas occidentales (lo que dio lugar a la "cuestión del otro") de América, Indias Orientales, Asia y África (p. 199).

4 Abya Yala es el nombre dado al continente americano por el pueblo Kuna que se encuentra entre los actuales Panamá y Colombia. Actualmente es usado por los pueblos y naciones indígenas, así como sus organizaciones, para notar que la dominación, explotación y conflicto se mantienen unidos por los procesos de colonización, neocolonización e imperialismo y, fundamentalmente, para hacer notar que dichos pueblos y naciones han resistido por más de 500 años ante este flagelo y siguen haciéndolo. Como territorio geocultural, el término Abya Yala es usado para referirse al continente y dejar de usar el término "América", de origen occidental. Usamos el concepto "Latinoamérica/Abya Yala" para referirnos a la multiplicidad de saberes, cosmovisiones y luchas indígenas, afros y mestizas, campesinas, étnicas y populares que integran nuestro territorio. En términos históricos, es viable pensar "Latinoamérica/Abya Yala" porque la herencia colonial conllevó procesos particulares en la formación de los Estados nacionales del siglo XIX, y configuró la región de manera diferente a lo sucedido en la parte norte de América/Abya Yala. 
Contrario a lo que el relato oficial de las relaciones internacionales señala, la actividad diplomática india ha sido parte sustancial de la formación y dinámica del sistema mundial moderno. Investigaciones muestran que los pueblos indios no han sido pasivos a los procesos de dominación y parte de esta respuesta fue la actividad diplomática indígena:

Detrás de la diplomacia indígena [contemporánea] hay una clara conciencia y un vivo recuerdo de negociaciones de larga duración (plasmada de distintas maneras: tratados, acuerdos, concesiones, títulos virreinales, etcétera) con los representantes de los poderes coloniales o con los gobiernos poscoloniales que los sustituyeron (Torres, 2013, p. 199).

Por centurias, pueblos indios y británicos, franceses, españoles, alemanes y portugueses alrededor del planeta "firmaron" acuerdos y tratados diplomáticos que sirvieron como arma de resistencia, supervivencia y participación en el sistema colonial (Langton, 2004).

Los encuentros diplomáticos que tuvieron lugar en los procesos coloniales fueron tensos, conflictivos y variaron con frecuencia entre los diferentes actores, regiones y épocas en que se produjeron. Mientras en Australia se vivió una experiencia colonial sin reconocimiento alguno de la autonomía indígena (Costa, 2006; Foley, Schaap y Howell, 2013; Wild, 1986), en Nueva Zelanda se firmó en 1840 el Tratado de Waitangi entre los Maorís y el Gobierno Británico, que ofreció ciertos reconocimientos y autonomías a los pueblos originarios. Afirma Langton (2004) que hechos similares se presentaron en el norte de América, donde los administradores de la colonia británica, entre 1533 y 1789, reconocieron a tribus indias análogas soberanías.

Una importante literatura muestra un largo proceso diplomático entre las colonias europeas y las naciones indias en el norte de América (Aquila, 1983; Jennings y Fenton, 1995; Havard, 2001; Midtrød, 2012). Las relaciones diplomáticas entre la confederación Iroquesa (las seis antiguas naciones indias) ${ }^{5}$ con alemanes, ingleses y franceses fue un fenómeno relevante (Jennings y Fenton, 1985). La Confederación de Naciones Indias Iroquesas fue reconocida por su diplomacia pre-colonial de alto nivel al promover acuerdos entre pueblos ancestrales -la "pax iroquesa" (Johnson, 2003). En los tiempos de la colonización se reconoce su papel como mediadora entre líderes indios y colonias inglesas. Cientos de tratados recuerdan y prueban la fuerte actividad iroquesa llevada

5 La Confederación Iroquesa fue constituida por tribus amerindias de lengua iroquesa que habitaban el noreste de Estados Unidos y el sureste de Canadá en la zona de los Grandes Lagos. Se cree que la fecha de su fundación fue probablemente entre 1450 y 1600. Originalmente fue formada por cinco tribus: cayuga, mohawk, oneida, onondaga y seneca. La tribu tuscarora se sumó en 1720. 
a cabo con los Países Bajos, Francia e Inglaterra (Aquila, 1997), y posteriormente con nuevos países de los Estados Unidos y Canadá, así como con otras naciones indias. Su herencia llega con contundencia incluso a la constitución de los Estados Unidos (Yarrow, 1987).

Más al sur, en la época colonial, dentro del territorio del imperio español y fuera de sus fronteras, la diplomacia indígena no fue menos importante. La diplomacia se caracterizó por dos fenómenos conocidos como pactismo y negociación (Levaggi, 2002; García, 1999; Contreras, 2007; Lázaro, 1999). Durante largas centurias, el orden colonial español fue incapaz de anexar a todos los pueblos indios. La monarquía se vio obligada a pactar para estabilizar la administración colonial y evitar las subversiones de otros indígenas, negros, mestizos o españoles empobrecidos que vivían dentro de los límites coloniales. Esto es lo que se conoce como pactismo: la diplomacia que se produce en los límites fronterizos entre las naciones "salvajes" que no pudo anexar el orden colonial.

Desde la perspectiva de la monarquía imperial, los tratados firmados con los pueblos indios fueron una estrategia de "pacificación". Las ideas medievales y los "justos títulos" que sustentaron la primera iniciativa de conquista fueron dando paso a una estrategia de "pacificación" materializada en las Ordenanzas de Nuevos Descubrimientos y Poblaciones promulgadas por Felipe II en Segovia el 13 de julio de 1573. Fueron extraídas del libro II del proyecto de Código de Indias de Juan de Ovando y, con posterioridad, volcadas en el libro IV, títulos I a VII, de la Recopilación de Leyes de Indias de 1680 (Levaggi, 2002).

La historia de la práctica diplomática hispano-india investigada por Abelardo Levaggi señala que las ordenanzas 139 y 140 desterraron la guerra como acción primera para la relación con los pobladores y la reemplazaron por "diligencia y santo celo (...) para traer la paz al gremio de la Santa Iglesia, y a nuestra obediencia a todos los naturales de la provincia" y más puntualmente convencerles de la siguiente forma:

Por vía de comercio y rescates para que traten amistad con ellos, mostrándolos mucho amor y acariciándolos, y dándoles algunas cosas de rescates a que ellos se aficionaren, y no mostrando codicia de sus cosas, asiéntese amistad y alianza con los señores y principales que pareciere ser más parte para la pacificación de la tierra (Levaggi, 2002, p. 19).

La tesis de Levaggi es que el texto jurídico pretendía desterrar la fuerza y establecer un proceso diplomático para construir amistad y alianza con los habitantes a través del buen trato, el comercio y los regalos. La "pacificación" se convirtió en la estrategia diplomática 
de la monarquía para atraer a caciques e indios como vasallos después de bautizarse y jurar fidelidad al Rey. El derecho diplomático emanado de los españoles reclamaba el reconocimiento natural de establecerse y poblar sin daño a los indígenas, colocando los cimientos de las relaciones de naturaleza contractual. Esto no deja de lado la violencia que estaba justificada cuando "previos requerimientos y trato amable aquellos indios no quería amistarse" (Levaggi, 2002, p. 20). La instrucción de Carlos V al obispo de México, Juan de Zumárraga, en 1543, quien los declaraba embajadores suyos en las tierras del Mediodía y Poniente, recomendó:

Procuraréis de confederarlos en perpetua amistad con nos y con todos nuestros súbditos y naturales, y asentaréis con ellos paces perpetuas (...) Habéis de asentar con los dichos Reyes, Príncipes y Repúblicas y comunidades que entre ellos y nos y nuestros súbditos pueda haber comercio y contratación de una parte a otra, y sobre ellos podáis poner las condiciones, limitaciones y cláusulas que os pareciere y viereis que conviene (...) Otrosí, habéis de trabajar con las dichas gentes por las mejores vías y maneras lícitas y convenientes que pudiereis de traerlos a ellos y a sus pueblos a nuestra amistad y obediencia, dándoles a entender nuestro principal fin, que es traerlos al conocimiento de un verdadero Dios, e introducirlos en la universal Iglesia (...) guardándoles todos sus privilegios, preeminencias, señoríos, libertades, leyes y costumbres con todas las otras condiciones y calidades que ellos debida y razonablemente os pidieren (Levaggi, 2002, pp. 20-21).

Aún más, la instrucción de Carlos $\mathrm{V}$ pretendía suscribir entre las partes:

Todos y cualesquier contratos, instrumentos, escrituras, asientos y capitulaciones que necesarias fueren y viereis que conviene, firmándolas y jurándolas vos por nuestra parte, y los Reyes y señores y principales entre ellos por la suya, como cosa que ha de ser guardada inviolablemente (Levaggi, 2002, p. 21).

La política pacificadora fue refinándose como fue el caso de la Instrucción sobre Nuevas Poblaciones de Valladolid (13 de mayo de 1556), que estableció poblaciones fronterizas para iniciar la evangelización y expansión del territorio. El texto jurídico evocó la autonomía de las partes y las intenciones de amistad y la no-agresión, aunque mantuvo la cláusula de guerra para quienes presentaban oposición a la predicación del Evangelio. Para ser justa la guerra, es decir, salir del campo diplomático, era necesario reunir cuatro condiciones: autoridad legítima, causa bastante, buena intención y modo conveniente. Por tanto, fue importante para la avanzada diplomática definir quiénes eran las naciones sometidas y las rebeldes -como lo hizo el Derecho de Gentes. A las primeras les era 
reconocido el derecho a la libre determinación, siempre que permitieran la evangelización, mientras que a las segundas directamente les era etiquetadas como vasallos infieles a los que era posible implantar castigo.

La estrategia diplomática de conquista fue refinada hasta reglamentar con "mayor calidad" la penetración y evangelización "pacífica" contenida en la Recopilación de Indias, en particular en las Ordenanzas de 1573. Los misioneros, en caso de no poder predicar y enseñar a los indios, deberían valerse de naciones convertidas para pacificar y convencer a los pueblos rebeldes. Basados en la "búsqueda de la paz", se establecieron pasos para atraer a los indígenas, convenciéndoles y haciéndoles requerimientos pertinentes.

La política de tratados para el control de territorios y poblaciones no fue homogéneo y permanente; se presentaron "periodos de fuerte actividad diplomática interétnica -en particular, ese siglo XVIII- y otros en los que fue débil y casi nula", aunque "tal debilidad y nulidad hay que atribuirla no a un cambio de la política oficial, sino a la presencia de circunstancias eventuales que hacían desaconsejable o imposible su puesta en obra, pero sin que llegase a afectar su vigencia general" (Levaggi, 2002, p. 21).

Quizás una de las más importantes y representativas figuras diplomáticas fue la institución del parlamento en la zona sur de América. Así lo expone Carlos Lázaro (1999):

Durante casi tres siglos mantuvieron con los hispanocriollos una pugna dialéctica de guerra y paz cuyo aspecto más relevante fue la aparición de una nueva forma de entendimiento, el parlamento. Esta institución política ya se hallaba presente en esencia tanto en las culturas indígenas americanas como en la europea, pero en el ámbito fronterizo americano adquirió un nuevo papel, con reglas distintas aceptadas por ambos bandos, y cuya expresión histórica se encuentra en los más de doscientos tratados de paz que se conservan en los archivos que, entre otros aspectos destacados, reflejan, aunque muy matizado por la fuente de transmisión, un elemento muy preciado por los investigadores americanistas: la palabra indígena (p. 645).

El parlamento fue una verdadera estructura diplomática donde los representantes de cada bando conocían las posturas y propuestas previamente trabajadas por los comisarios de las naciones. La celebración duraba varios días, intervenían varias personas y se desarrollaba con gran formalidad en presencia de público. Los protocolos y ritualidades eran fundamentalmente mapuches, muchas veces incomprensibles para los españoles, pero determinante para su validez, ya que "para los mapuches significaba cumplir con las leyes de la tradición y del Ad-mapu” (Contreras, 2007, p. 95). 
La otra figura diplomática fue "la negociación" que se presentó al interior del orden colonial. Es una figura que se diferencia del pactismo porque los pueblos indios no tenían una autonomía plena, habían sido "colonizados" o "conquistados" y quedaban dentro del derecho colonial. Aun así, existía un grado de autonomía y reconocimiento de una entidad diferenciada que usualmente tenía representantes ante la administración colonial.

Los tlaxcaltecas negociaron con la administración colonial sus pretensiones, argumentando su alianza y apoyo a Hernán Cortés durante la conquista a Tenochtitlan; uso estratégico que les permitió buscar beneficios o reconocimientos en un medio de alta hostilidad. Otros indios argumentaron su apoyo a la conquista de Yucatán para no pagar los tributos que les fueron impuestos. Delfina López afirma que la nobleza indígena con frecuencia recurría a la historia de su linaje prehispánico reconocido y validado por la monarquía (López Sarrelangue, 1965). El régimen instaurado otorgó a la nobleza indígena beneficios, les concedió tierras y encomiendas, atribuyó rentas y la confirmación de caciques y gobernadores en sus localidades. Parcialmente, la monarquía permitió a algunos nobles -generalmente quienes fueron aliados en la conquista- "compartir" parcialmente el gobierno del nuevo sistema (Romero, 2003). Sin embargo, décadas adelante, con la irrupción de las independencias, hay un cambio en las prácticas diplomáticas que por largo tiempo se establecieron en y con el orden colonial. En la República, la tendencia de homogenización de la nación criolla a través de una estrategia de "igualación" rompió la diplomacia interna y de frontera, dando fin a la era del pactismo y la negociación.

La formación y consolidación del Estado nacional planteó un nuevo problema a la producción de la alteridad y la actividad diplomática que hasta entonces había gobernado el orden colonial. Los antiguos territorios indígenas fueron violentamente diluidos en la gramática jurídica del Estado nacional. Con las independencias se dio paso a la diplomacia interestatal. Sin embargo, bajo el manto de la soberanía nacional quedaron atrapadas las condiciones de una diplomacia indígena doméstica.

En este contexto, pueblos y naciones indígenas se vieron obligados a desarrollar nuevas estrategias de supervivencia, resistencia y acomodamiento estratégico que en términos diplomáticos se presentaron como "negociación" con el Estado nacional y como pactismo en su última fase. El pactismo con los mapuches trascendió al orden colonial y se mantuvo durante la formación de las repúblicas de Chile y Argentina. En principio, la independencia de las Provincias Unidas del Río de la Plata buscó incluir a los mapuches bajo una proclama de hermandad con el objetivo de ampliar las fronteras heredadas de la colonia. En 1812 fue celebrado el primer acuerdo con los mapuches en la era republicana, conocido como el Parlamento de San Carlos, y el último fue en 1878, con 
el Tratado de Paz entre el Gobierno Nacional y los Caciques Ranqueles. En este periodo se celebraron alrededor de cuarenta tratados de paz, convenios y parlamentos. Al final del siglo XIX, violando los acuerdos, el ejército argentino invadió el territorio mapuche con "La Conquista del Desierto". Una suerte similar corrieron los mapuches con la república chilena, con quienes celebraron parlamentos y tratados hasta su posterior dominación militar (Contreras, 2010; Acosta, 2010). Bajo la forma Estado, la tradición del pactismo fronterizo quedó aniquilada.

Aunque la república quiso abolir las estructuras de gobierno del antiguo régimen, el uso del aparto jurídico para la movilización, la presión y la negociación colectiva y estratégica fueron la constante respuesta de los pueblos indios a este nuevo proceso de dominación en el campo de lo que llamamos diplomacia. Dentro de las fronteras nacionales quedaron apresadas las fuerzas plurales, conllevando a un fenómeno conocido como la diplomacia indígena doméstica. Noé Cornago, con la noción de teratologías diplomáticas, afirma que las voces plurales laten al interior de los Estados nacionales y se promueven prácticas diplomáticas derivadas de dichas fuerzas (Cornago, 2013). La palabra teratología es tomada de aquellas figuras "anormales", malformaciones o deformaciones que desfiguran el "patrón común". El patrón "común" de la diplomacia sería la relación interestatal, empero dentro del Estado conviven naciones o pueblos que son invisibilizadas dentro de la lógica nacional, situación que recientemente vino a ser evidente en países como Ecuador o Bolivia, que reconocen su conformación plurinacional.

Ethelia Ruiz considera que los indios -tanto en la república como en el orden colonialdesarrollaron su gran capacidad de negociación y adaptación para defender sus tierras. La estrategia de defensa fue el uso de títulos primordiales para la tenencia de la tierra:

Diversos pueblos de todo México comenzaron a solicitar sus papeles al Archivo General. Los documentos, que eran entregados como copia de los títulos a los pueblos durante el siglo XIX, provenían generalmente del ramo de Tierra de este archivo, y consistían en diversos documentos coloniales, como mercedes, fragmentos de litigio, mapas, etc. (...) Los relatos y las historias locales plasmados en algunos títulos coloniales continuaron teniendo utilidad legal para los pueblos indios y fueron copiados -y en ocasiones traducidos- por empleados del archivo para ser utilizados como instrumento legal... Otros pueblos que conservaban documentos antiguos se dieron a la tarea de actualizar sus mapas, inscribiendo en ellos la información de sus mojoneras, para presentarlos ante los tribunales con el fin de amparar sus tierras comunales. En otros casos los pueblos decidieron mandar elaborar sus propia documentación y hacerla pasar por antigua, fenómeno similar a lo que ocurrió en la

152 Si Somos Americanos. Revista de Estudios Transfronterizos 
época colonial con los títulos primordiales y con los códices de tipo Techialoyan (Ruiz Medrano, 2010, p. 21).

Algunas coincidencias hay con el movimiento de los caciques generales (1880-1900) y de los caciques apoderados (1912-1952) en Bolivia. Entre 1912 y 1914 fueron nombrados los primeros caciques (principalmente en La Paz, Cochabamba y Potosí) por los comunitarios (Ríos Montero, 2002) ${ }^{6}$. El cacique apoderado, a diferencia del cacique que es un dirigente político, es nombrado por la autoridad del Ayllu (jilaqatas) para cumplir tareas de representación y gestión ante las autoridades. Los primeros caciques apoderados basados en su representación solicitaron al mismo Presidente de la República enfrentar los abusos de las autoridades locales. El proceso de recuperación de tierras usurpadas por el régimen de las haciendas del altiplano conllevó a levantamientos, movilización y negociación. Roberto Choque Canqui (2011) caracteriza este proceso al señalar lo siguiente: "Fuese mediante gestiones ante las autoridades en base a documentos o a través de las rebeliones, la lucha por la recuperación de las tierras despojadas a los indígenas fue una constante que se ha mantenido en el tiempo" (p. 109). Los caciques apoderados de acuerdo a sus atribuciones representaron los intereses de las comunidades como delegados para la defensa de las tierras originarias contra los terratenientes y la defensa de la vida colectiva de los abusos de los gobiernos locales.

En Colombia, el célebre luchador indígena del pueblo Nasa, Manuel Quintín Lame (1880-1967), emprendió una larga carrera de pleitos contra el Estado en defensa de los comuneros de los departamentos del Cauca y del Tolima. Trabajó con intensidad para recuperar documentos legales -títulos y cédulas reales de los resguardos- que le permitieran proyectar sus demandas políticas para reconstruir o garantizar los mojones territoriales de su pueblo. Su lucha era hacer respetar la propiedad colectiva reconocida en el orden colonial cuando los caciques nasa dirigieron escritos -en castellano o con su propia "escritura" - que definían las listas censales, títulos de tierras y testamentos.

La negociación de la diplomacia doméstica no es de carácter separatista, pero está sustentada en el proyecto sociocultural e histórico de los pueblos que se diferencian de la nación criolla. Incluso, sintiéndose parte de una comunidad más grande (la nacionalestatal), las reivindicaciones indias no perdieron el carácter propio de su entidad social y la "identidad" formada por otros saberes y cosmovisiones.

6 Otra fuente, la principal, ha sido el THOA - Taller de Historia Oral-, que desarrolló trabajos importantes con los descendientes de los caciques apoderados y con sus comunidades como parte de la recuperación y reivindicación de la memoria viva de la lucha ancestral. 


\section{Diplomacia indígena y globalización}

La diplomacia indígena contemporánea es una expresión de la diplomacia desde abajo7. Es parte de los procesos diplomáticos que emergen de la globalización contrahegemónica o de la globalización desde abajo. Desde las décadas de los setenta y ochenta del siglo $\mathrm{XX}$, la diplomacia indígena salió progresivamente de las fronteras nacionales en las que estuvo apresada durante la consolidación del Estado nacional para reclamar sus derechos de autodeterminación y autonomía (Arévalo Robles 2011a; Arévalo Robles, 2011b). Sus más particulares medios fueron la incidencia política (negociación, cabildeo y defensa) en escenarios internacionales, regionales y transnacionales, y el creciente acercamiento regional y continental de los diferentes pueblos y naciones indígenas (Campañas, Encuentros y Cumbres Continentales Indígenas).

La emergente diplomacia indígena contemporánea o diplomacia indígena desde abajo (en adelante diplomacia indígena) surge y se consolida en el derrotero histórico del fracaso del indigenismo de Estado y el agotamiento del modelo nacional de desarrollo. En las últimas décadas del siglo anterior, el indigenismo fue denunciado por actores como la Iglesia, grupos profesionales y las ONG y, por el contrario, reivindicaron la identidad indígena, su defensa y preservación. El proceso abrió un debate continental que comenzó a fracturar el indigenismo de Estado. Este primer giro generó un tipo de indigenismo "protector", pero con el tiempo fue asumido directamente por los propios pueblos ancestrales.

La urbanización indígena, producto del modelo de la modernización industrial ${ }^{8}$ y el fracaso de las reformas agrarias en los setenta, puso en alerta a los líderes indios, que vieron en la integración económica y sus modelos de explotación un peligro a sus sistemas sociales ancestrales y ecosistemas. En consecuencia, la integración que persiguió "las reformas agrarias al acortar la distancia entre lo urbano y lo rural" se vio reflejada "en la aparición de numerosos movimientos y organizaciones sociales que reivindican su especificidad etnocultural, en la medida que manejan los códigos de la sociedad criolla" (Bengoa, 2007, p. 242).

La diplomacia desde abajo toma forma en experiencias particulares de actores subalternos que buscan enfrentar los retos y riesgos de la globalización desde nuevas formas diplomáticas. Diplomacia de los pueblos, diplomacia indígena, diplomacia popular, diplomacia ciudadana, diplomacia guerrillera, diplomacia de las ONG, diplomacia de la sociedad civil y muchas otras diplomacias ad hoc o sostenidas, son nombres que recogen la emergente actividad diplomática contemporánea a finales del siglo XX y principios del siglo XXI. Su nombre procede del concepto de globalización desde abajo de Boaventura de Sousa Santos (2009).

8 Dichas transformaciones son más evidentes en las principales ciudades latinoamericanas, como El Alto de La Paz en Bolivia; en Lima, Perú, con el fenómeno del acholamiento; y la presencia urbana mapuche en Santiago de Chile.

\section{Si Somos Americanos. Revista de Estudios Transfronterizos}


La demanda indígena de los sesenta -ligada a la tierra- fue integrada lentamente a las reivindicaciones étnicas, al reconocimiento de las lenguas y la creación de un sistema educativo bilingüe y bicultural. Los ochenta y principalmente los noventa verán el florecimiento de una gramática de lucha articulada a las nociones de autonomía y autodeterminación. Ya no se busca la integración a la sociedad, sino el reconocimiento de la diferencia étnica, y se denuncia el etnocidio nacionalista. La autonomía indígena se convirtió en el centro que irradia la lucha indígena y abrió el debate con las viejas nociones del Estado nacional, soberanía, territorio, autoridad, legitimidad y jerarquía jurídica. La idea de autonomía creó una gramática compartida por las luchas indígenas a lo largo y ancho del planeta.

Una importante influencia a este proceso fueron actores no-indígenas, como las ONG, la Iglesia, las organizaciones de académicos y profesionales críticos. Indígenas y actores no-indígenas como organizaciones no-gubernamentales conformaron redes de defensa. En principio, imbuidos por el viejo indigenismo y posteriormente por una particular articulación del indianismo y ciertas posiciones posmodernas (Bengoa, 2007), se preocuparon por abrir escenarios para que los pueblos indígenas expresaran su voz y tejieran sus propuestas desde sus posiciones político-identitarias.

Las organizaciones académicas, especialmente ligadas a la antropología, también participaron de dicho impulso de interacción transnacional e internacionalización de los temas indígenas. Henri Favre (1998) explica que una nueva generación de antropólogos en los setenta cuestionó la reproducción de los sistemas de dominación a partir de la disciplina y manifestaron la necesidad de poner la producción intelectual al servicio de la causa indígena. En el año 1971 se produjo lo que algunos llaman el hito fundacional de la transnacionalización e internacionalización de la causa indígena: la Declaración de Barbados, producida en el simposio de antropólogos sobre la "Fricción Interétnica en América del Sur", donde participaron reconocidos sociólogos, como Darcy Ribeiro y Guillermo Bonfil. Dicha declaración abrió una agenda de trabajo sobre la promoción internacional de la autodeterminación indígena y "la lucha de liberación de los indígenas" (Bottaso, 1992), convirtiéndose en un antecedente del multiculturalismo al equiparar la cultura occidental y la india como complementarias. Esto se hace evidente en la resolución firmada por el Permanent Council of the International Union of Anthropological and Ethnological Sciences al declarar en Tokio (1968) lo siguiente:

1. We protest and repudiate genocide, and the use of force as an instrument of cultural change, in programs of social, economic and political development, and in the separation of indigenous peoples from their land. 
2. We request the governments concerned to institute effective protection under the law for indigenous peoples, and to discipline government officials and others guilty of actions that contravene the International Declaration of Human Rights.

3. We urge governments, anthropologists, and others to re-examine current policies in order to provide ethically just and scientifically enlightened programs of acculturation which allow the peoples concerned a free and informed basis for choice (Sanders, 1977, p. 5).

En 1968 nació la red de investigadores y activistas de derechos humanos comprometida en asuntos indígenas (International Work Group for Indigenous Affairs, IWGIA) (Sanders, 1977), que poco a poco fue sumando activistas indígenas de América del Norte y también del Ártico, Oceanía, Rusia y África. Un año después fue fundada la organización internacional Survival por la defensa de los pueblos indígenas del mundo. En el mismo año se constituyó el Netherlands Centre for Indigenous Peoples, WIP/ NCIV, Cultural Survival (1972) y Gesellschaft für Bedrohte Völker en 1968, en principio como oposición al genocidio en Biafra, abriendo un frente de defensa de los derechos humanos.

La destacable función de las organizaciones no gubernamentales fue la presión transnacional para promover, facilitar y dirigir transformaciones concretas en las normas globales y sus prácticas cuando los canales locales de comunicación en el orden local (entre pueblos indígenas y Estado) estaban bloqueados (Sanjeev, Riker y Sikkink, 2002). Las ONG pudieron hacerlo al desarrollar políticas de información que pusieron en consideración pública las situaciones a las que se enfrentan los grupos sociales que apoyaban. Usaron políticas simbólicas, política de palancas con el uso y movilización de apoyos e influencias y la cooptación de apoyo de políticos responsables (Keck y Sikkink, 2000). La relación entre organizaciones indígenas y organizaciones no-gubernamentales permitió fortalecer mucho más la internacionalización de la causa indígena y la transnacionalización del activismo indígena (Stavenhagen, 1998).

IWGIA interactúo al principio con los gobiernos escandinavos, de quienes recibió sus primeros recursos para el desarrollo de su labor (publicaciones, apoyo a organizaciones indígenas, campañas de denuncia, cabildeo internacional, etc.), como lo reconocen al afirmar:

The liberal, political and cultural traditions of governmental support to NGOs in Scandinavia are very different from the situation in countries such as the UK, Germany, France and the U.S. Without support from the Scandinavian governments, IWGIA 
would not have been able to develop as an international organisation, publishing in non-Scandinavian languages and often working in countries that are of minor significance to Scandinavian development aid (Dahl, 2009, p. 170).

Dichas organizaciones al obtener recursos por vía de donaciones privadas y/o subvenciones públicas hicieron posible el funcionamiento y desarrollo de los proyectos sobre los que se fundaron y fortalecieron las interconexiones transnacionales (redes de defensa, grupos de coordinación, encuentros y cumbres). Uno de los más importantes propósitos de las ONG fue "canalizar recursos hacia los países del sur" para apoyar organizaciones indígenas y entablar acciones compartidas enfocadas en "campañas de sensibilización de la opinión pública, de educación para el desarrollo y valores solidarios, así como de presión (lobby) y denuncia ante los gobiernos en torno a los problemas de los pueblos del sur y los factores internacionales que los causan” (Murguialday, 2006).

Las ONG apoyaron a las organizaciones indígenas para que llegaran y participaran en las Naciones Unidas. En la década de los setenta y principios de los ochenta, las organizaciones indígenas y no-indígenas -tales como International Indian Treaty Council (IITC), Inuit Circumpolar Council (ICC), Sámi Council, International Work Group for Indigenous Affairs (IWGIA) y Anti-Slavery International- lograron acreditar un número de organizaciones indígenas que no estaban autorizadas para participar. Incluso después de que las Naciones Unidas permitieron la intervención de organizaciones sin que mediaran las ONG, apoyaron financieramente la participación de indígenas de Asia, África, América Latina y Rusia.

En las regiones del Ártico, Latinoamérica, Norte América, Asia, Oceanía y África se fueron organizando y articulando iniciativas para movilizar su lucha a partir de prácticas diplomáticas que buscaron incidir en la política internacional, en la región y en "sus" Estados. En 1977 fue creado el Consejo Internacional de Tratados Indios (CITI) como organización de pueblos indígenas de Norte, Centro, Sudamérica, el Caribe y el Pacífico, que a la postre se convertiría en la primera organización indígena reconocida con estatus consultivo ante el Consejo Económico y Social de las Naciones Unidas (ECOSOC). El CITI fue, además, la primera organización indígena ascendida -en julio de 2011- al "Estatus Consultivo General" ante ese mismo organismo, en reconocimiento a su amplia participación de larga data en el sistema de las Naciones Unidas, para representar las inquietudes de los pueblos indígenas y trabajar en la elaboración e implementación de normas y mecanismos internacionales para el reconocimiento de los derechos de los pueblos indígenas. 
Para la década de los noventa el tejido transnacional tenía un cuerpo propio. Articulaban iniciativas, compartían información y adelantaban acciones conjuntas tanto a nivel internacional como a nivel regional, nacional y local. Actualmente las organizaciones y espacios que trascienden las fronteras en alianza para la formulación de agendas y proyección de acciones políticas indígenas es inmenso. Como escenarios transnacionales de coordinación regional y continentales contamos con: Arctic Athabaskan Council, AAC; Asia Indigenous Peoples' Pact, AIPP; Asian Indigenous Women's Network, AIWN; Alianza Estratégica Aymaras Sin Fronteras (Municipios aymaras de Chile, Perú, Argentina y Bolivia); Asia Pacific Indigenous Youth Network, APIYN; Coordinadora Andina de Organizaciones Indígenas, CAOI; Consejo Indígena de Centro América, CICA; Coordinadora Latinoamericana de Organizaciones del Campo, CLOC; Coordinadora de las Organizaciones Indígenas de la Cuenca Amazónica, COICA; Enlace Continental de Mujeres Indígenas (espacio para las mujeres indígenas que permite intercambiar experiencias y buscar alternativas conjuntas); Foro Internacional de Mujeres Indígenas, FIMI; First Peoples Worldwide; Gwich’in Council International, Canadá y Alaska, GCI; Alianza Internacional de los Pueblos Indígenas y Tribales de los Bosques Tropicales, IAITPTF; Indigenous Environmental Network, América del Norte, IEN; International Indian Treaty Council, IITC; International Indigenous Youth Conference, IIYC; Inuit Circumpolar Conference; Indigenous Peoples of Africa Co-ordinating Committee, IPACC; Nación Taína de las Antillas (Nuevo Amanecer Taíno, República Dominicana, Cuba y Puerto Rico); Parlamento Sami del Norte de Europa, SÁMIRÁDDI; Indigenous Peoples' International Centre for Policy Research and Education, TEBTEBBA; United Confederation of the Taino People, UCTP; y Vía Campesina (Movimiento Campesino Internacional).

En resumen, señala Alison Brysk (2009) que este escenario internacional-transnacional fue alentado por la transición a la democracia en los años ochenta en América Latina, la formación de intelectuales indígenas urbanos y la mayor presencia de ONG, misioneros, periodistas, ecologistas y representantes de la cooperación internacional en sus territorios, que terminó por "articular un tráfico del pueblo global hacia el pueblo tribal" (p. 89) y después una relación del "pueblo tribal" hacia el global.

\section{Aspectos funcionales y tipológicos de la diplomacia indígena contemporánea}

En los últimos casi cuarenta años, la actividad diplomática indígena se ha caracterizado por una permanente incidencia política en escenarios internacionales y transnacionales para influir 
decisiones, discursos, programas y prácticas de la política global que le atañen directamente a sus pueblos y territorios. Ha sido un trabajo arduo y constante de negociaciones, cabildeo y defensa que produjo, entre los resultados más visibles y significativos, la Declaración de las Naciones Unidas sobre los Derechos de los Pueblos Indígenas adoptada en Nueva York el 13 de septiembre de 2007 durante la sesión 61 de la Asamblea General de las Naciones Unidas. Incidencia política que logró ser exitosa por el desarrollo de una práctica diplomática ancestral para el acuerdo, discusión, análisis y negociación de gramáticas políticas entre pueblos indígenas, denominada complementariedad diplomática.

La incidencia política y la complementariedad diplomática son dos prácticas diplomáticas determinantes para la mediación entre representantes de diferentes pueblos y naciones indígenas con actores estatales y no-estatales de la más diversa naturaleza, con los que se han encontrado como aliados o contradictores en un estado permanente de acuerdo, conflicto y negociación, motivado por la defensa y promoción de la autodeterminación y la autonomía ancestral. Ambas prácticas han producido fenómenos diplomáticos significativos a nivel internacional y regional, que hemos diferenciado como diplomacia indígena internacionalizada y diplomacia de la complementariedad.

\section{Incidencia política y diplomacia internacionalizada}

La noción "diplomacia indígena internacionalizada" remite al traslado de un asunto político, jurídico, económico- de lo local-nacional hacia lo mundial, apostando por la influencia de la política global dentro de organismos internacionales para lograr objetivos políticos sobre el Estado nacional.

La diplomacia indígena internacionalizada inicia en los órganos de derechos humanos de la ONU, particularmente en el Grupo de Trabajo de Naciones Unidas sobre Poblaciones Indígenas, creado en 1982, y luego expandida a otros escenarios ${ }^{9}$ para influenciar la agenda internacional en temas como desarrollo, medio ambiente, comercio, finanzas, infancia, juventud, mujer, tratados internacionales y derecho al territorio, ente otros. El principal mecanismo de participación en el ecosistema onusiano fue la incidencia política, entendida como la actividad diplomática que busca influenciar la adopción de normas

9 Por ejemplo, llevó a la creación del grupo de trabajo sobre el proyecto de declaración sobre los derechos de los pueblos indígenas (1995), el Foro Permanente para las Cuestiones Indígenas (2001), Relator Especial sobre la situación de los derechos humanos y las libertades fundamentales de los pueblos indígenas (2001) y el Mecanismo de Expertos sobre los Derechos de los Pueblos Indígenas (2007), entre los principales del Sistema de las Naciones Unidas. 
internacionales de protección de los derechos indígenas; crear consciencia a la comunidad internacional sobre su situación social, económica y política; y movilizar la voluntad de múltiples actores para que sean favorables a sus demandas y propuestas.

La incidencia política se viene desenvolviendo al menos por tres prácticas diplomáticas, conocidas como el cabildeo, la defensa y la negociación. Carlos Crespo explica que la negociación, vista desde los movimientos sociales, -más que un llamado a la cooperación es un dispositivo para reducir las relaciones dominación (2005). Es un dispositivo de resistencia que aspira alterar los juegos de verdad y sus reglas, y por ende, la modificación de las condiciones de producción de regímenes de verdad. En clave foucultiana, Carlos Crespo (2005) reconoce que la negociación es un juego de acciones sobre acciones, con la posibilidad "de influir, dirigir, orientar o determinar la conducta y/o comportamiento del otro" (p. 239).

Los representantes indígenas -en su tránsito por las Naciones Unidas por medio de la negociación- han enfrentado las gramáticas de la verdad jurídica, promoviendo la protección de los derechos de los pueblos indígenas. El caso emblemático es la negociación de la Declaración de la ONU sobre los Derechos de los Pueblos Indígenas, que duró más de veinte años; negociaciones álgidas que retaron al derecho internacional y su privilegio a la soberanía estatal. Con difíciles negociaciones, incluso entre los mismos representantes indígenas, lograron influir la voluntad de representantes estatales para que vieran la conveniencia de contar con una herramienta jurídica de protección para los pueblos indígenas sin que se viera socavada o puesta en duda la unidad del Estado. Diplomáticos indígenas se enfrentaron a Estados tan poderosos como Canadá, Nueva Zelanda, Australia y Estados Unidos (CANZUS), quienes se negaron por largos años a aceptar gramáticas que atentaran con lo que consideraban "temas internos" o reivindicaciones contra la costumbre y el derecho internacional. Basta decir que las negociaciones agruparon, también, algunos Estados que apoyaron la apuesta de los diplomáticos indígenas, conllevando a verdaderas estrategias de resistencia contra los pesos hegemónicos de las relaciones diplomáticas instauradas.

La propia participación en las Naciones Unidas -y su efectividad- fue parte de las negociaciones. En algunos casos las negociaciones fueron exitosas, como en el caso del Foro Permanente, donde Estados y representantes indígenas llegaron a acuerdos favorables sobre las formas de participación. Mientras, en otros escenarios onusianos su voz es marginal, como en el caso de los derechos humanos y las empresas transnacionales. En todo caso, las negociaciones, el cabildeo y defensa trajeron a la agenda global el reconocimiento de los pueblos indígenas como "pueblos sin Estados", y la necesaria refundación de una relación de igualdad y paridad con "sus" Estados, anteriormente desconocida por el derecho internacional. 


\section{Complementariedad diplomática y diplomacia complementaria}

La complementariedad diplomática es la práctica diplomática entre pueblos indígenas para "articular los diferentes esfuerzos, experiencias y propuestas políticas que permiten a las organizaciones llegar a escenarios internacionales con planteamientos respaldados por todas, para garantizar una mayor incidencia y respaldo político" (CAOI, 2013, p. 2). La complementariedad diplomática es la negociación de significados políticos en escenarios que progresivamente fueron estableciendo un escenario de diplomacia complementaria o diplomacia entre los pueblos y naciones indígenas. El mejor ejemplo son los encuentros y cumbres continentales de pueblos indígenas convocados por sus propias organizaciones al menos desde 1990 en América Latina.

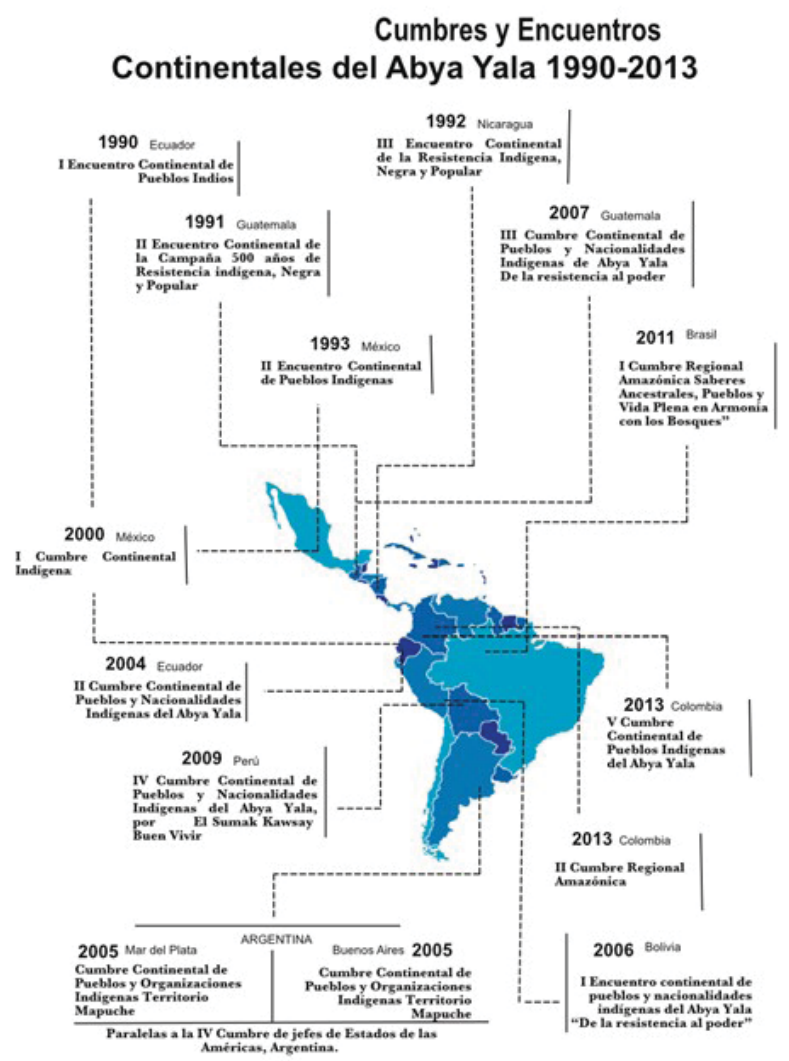

Elaboración propia. Gabriel Andrés Arévalo Robles

Ilustración 2. Mapa de Encuentros y Cumbres Continentales del Abya Yala 1990-2013 
Encuentros y cumbres surgieron como mecanismos estratégicos continentales de aproximación entre diferentes líderes, representantes, pueblos y organizaciones indígenas, motivados por un fortalecimiento de los movimientos indígenas nacionales, en medio de un ambiente convulsionado por las medidas neoliberales. Progresivamente se convirtieron en oportunidades de liderazgo en el continente Abya Yala-América y se caracterizaron por discutir temas coyunturales y estructurales, acercando a líderes y representantes indígenas para compartir experiencias e ideas, tejer conjuntamente propuestas e iniciativas, motivar a los actores no-indígenas para que se sumen a sus luchas e impactar a la opinión pública regional y mundial a favor de sus demandas y propuestas.

La expresión más concreta de la diplomacia de la complementariedad es la interconexión creciente entre pueblos indígenas en encuentros, congresos o cumbres convocados, organizados y desarrollados por ellos mismos para abordar cuestiones en el ámbito de las políticas del desarrollo, la educación, la salud, la comunicación, las leyes, el género y la guerra. Esta tendencia diplomática ha crecido desde finales del siglo XX y se ha masificado por todas las regiones y continentes. A partir de principios de la década de los noventa, los pueblos indígenas del continente Americano - al que han llamado Abya Yala-intensificaron su diplomacia transnacional en el marco de la "Campaña 500 Años de Resistencia Indígena y Popular", que tiene como hito fundacional la Declaración de Quito (1990), manifestación continental contra las celebraciones oficiales de los quinientos años del "descubrimiento de América".

Usualmente la diplomacia interestatal evoca la lucha por el poder político y se erige como un instrumento de paz en su versión de coerción, como lo afirmaba Morgenthau (1986) al decir: "si hubiera alguna forma para desterrar la lucha por el poder en el escenario internacional, la diplomacia desaparecería" (p. 627). El impulso diplomático entre pueblos indígenas es de naturaleza diferente a la diplomacia eurocéntrica e interestatal. La diplomacia estatal se basa en los intereses nacionales, interpreta el mundo como un sistema anárquico que solo puede ser estabilizado por el equilibrio de poder y que solo puede cooperar cuando son negociados los intereses de cada uno de ellos. Esta visión de la diplomacia se basa en una concepción negativa del ser humano y por tanto es fundamentalmente racionalinstrumental.

La diplomacia de la complementariedad es una concepción diferente de la diplomacia, tanto por el sentido que la anima (solidaria, colaborativa, diversa, respetuosa, anti-imperialista) como por su procedencia (de los pueblos, de grupos y comunidades "desde abajo"). La diplomacia estatal eurocéntrica evoca la relación entre entidades políticas estatales y se preocupa por mantener, negociar y cooperar a partir de intereses propios y particulares. La

\section{Si Somos Americanos. Revista de Estudios Transfronterizos}


diplomacia indígena convoca en su práctica diplomática a todas las relaciones del cosmos y se preocupa por recrear todas las relaciones, interconexiones e interdependencias como armónicas y equilibradas; el fin último no son los intereses de una nación o pueblo, sino el sostenimiento de las relaciones armónicas que incluyen la supervivencia y buen vivir de dichos pueblos, sus ecosistemas y su interacción sostenible. La diplomacia occidental comprende a la naturaleza y sus recursos como una ventaja o desventaja en la negociación de intereses, mientras la diplomacia indígena la entiende como un ser inmanente en sus relaciones, que por estar viva y coparticipar del acto diplomático anima el deber ético de respetarla, sostenerla y defenderla para el sostenimiento de la vida en sí misma. Los protocolos diplomáticos occidentales emanan de la racionalidad humana inspirada en la relación de sujeto-objeto: saludo a la bandera, himnos nacionales, paradas militares. Los protocolos diplomáticos indígenas emanan de la cultura de la relacionalidad, donde los humanos - pero también el fuego, el cielo, el agua y la movimientos celestes- son copartícipes del encuentro diplomático; por tanto, sus rituales y ceremonias los incluyen como participantes activos y decisivos: ritual de limpieza y armonización, ceremonia del fuego.

Normativamente, en la diplomacia entre pueblos indígenas subyace el principio de complementariedad que asume la diferencia y lo opuesto como entidades interconectadas e interdependientes que funcionalmente permiten la sostenibilidad de la vida por medio de la búsqueda del equilibrio como reciprocidad (no como poder). La diplomacia ancestral normativamente pretende ser complementaria por medio de la reciprocidad, entendida como la corresponsabilidad de las mutuas actuaciones y que tiene como fin la distribución equitativa, la redistribución y la compensación entre las acciones de cada entidad. La diplomacia de la complementariedad está inspirada en los mismos principios que animan la diplomacia desde abajo: antiimperialismo, descolonización, solidaridad, diversidad, cooperación, resistencia y hermanamiento como sustento de las relaciones humanas armónicas y equilibradas.

En la memoria subyacen las categorías y lógicas de interacción, encuentro y comunicación de los pueblos y naciones indígenas, con prácticas y protocolos que evocan múltiples mediaciones, como la "diplomacia del Ayllu, que se sustenta en compartir y comunicarse entre todos por medio de la [hoja de] coca... en ceremonias protocolares como el akhulli" donde:

Los participantes en el acto entraban a un proceso oral sagrado o ceremonial, en igualdad de condiciones y con los mismos derechos. Se dice que en el akhulli se tenía que agotar la conversación dentro de los marcos amistosos, dejando de lado los odios 
y resentimientos, hasta encontrar una solución para las partes y "hasta que pose el cóndor sobre el pijchu” (Escuela Diplomática Plurinacional, 2009a, pp. 7-8).

Mediaciones de ancestral diplomacia que se desarrollan bajo "un pensamiento inclusivo y abierto para entender y compartir nuevas formas y costumbres, sin discriminación, convocando los principios de la reciprocidad y compartimiento festivo, valores muy sanos para la pervivencia de la comunidad como unidad comunal y política" (Escuela Diplomática Plurinacional, 2009b, p. 4).

La mediación entre pueblos y naciones indígenas que da sentido a la diplomacia indígena son "prácticas de vida portadoras de valores que discrepan de las formas occidentales, consideradas más individualistas y despersonalizadas" y que se convierten en la recreación étnica-identitaria contemporánea que apuesta por relacionamientos que, según Fernando Huanacuni Mamani, convoca a "diferentes pueblos, diferentes visiones, diferentes formas de vida, pero con un solo paradigma: el paradigma comunitario que está inmerso en los diferentes pueblos antiguos" (Huanacuni, 2012, p. 26).

Estos principios constituyen el fondo de la idea de complementariedad como principio aplicado a la vida física, espiritual y social, tal como es ratificado en las Declaraciones Continentales de los Pueblos Indígenas del Abya Yala:

Ratificamos nuestros principios milenarios, complementariedad, reciprocidad y dualidad, y nuestra lucha por el derecho al territorio, la Madre Naturaleza, la autonomía y libre determinación de los pueblos indígenas (III Cumbre Continental de Pueblos y Nacionalidades Indígenas del Abya Yala, 2007, p. 1).

Nosotros, los Pueblos y Organizaciones Indígenas del Continente de Abya Yala América- reunidos en territorio ancestral del Pueblo Mapuche, primeramente invocamos la cosmovisión de nuestros mayores y siguiendo el camino trazado por ellos, en un marco de unidad y armonía entre nosotros y con nuestra madre naturaleza (Cumbre Continental de Pueblos y Organizaciones Indígenas, celebrada en territorio mapuche, Mar del Plata, Argentina, 2005, p. 2).

Somos pueblos originarios de Abya Yala. Nuestros antepasados, nuestros abuelos nos enseñaron a amar y venerar nuestra fecunda Pacha Mama, a convivir en armonía y libertad con los seres naturales y espirituales que en ella existen. Las instituciones políticas, económicas, sociales y culturales que tenemos son herencia de nuestros

164 Si Somos Americanos. Revista de Estudios Transfronterizos 
antepasados y son la base para la construcción de nuestro futuro (II Cumbre Continental de los Pueblos y Nacionalidades Indígenas de Abya Yala, 2005, p. 1)

En breve, la diplomacia de la complementariedad-expresada en la historia de los Encuentros y Cumbres Continentales de los Pueblos Indígenas del Abya Yala entre 1990 y 2013 y los Encuentros y Cumbres Continentales del Mujeres Indígenas del Abya Yala (1995 y 2013)-son dos fenómenos de actual diplomacia que emulan los procesos de complementariedad como procesos de acercamiento, encuentro y articulación de las organizaciones y movimientos sociales que nos permiten desentrañar las nuevas interconexiones que definen y moldean el sistema mundial.

\section{Conclusión}

La diplomacia indígena es una práctica de resistencia histórica estratégica y de "baja intensidad". A pesar de ser una diplomacia menos determinante que la Estatal, es concluyente como práctica política de la "sociedad civil global" e influyente tanto en los territorios locales como en los regímenes internacionales. La intensa actividad diplomática demuestra que los pueblos indígenas han crecido y fortalecido como actores internacionales, rivalizando con las nociones de la política moderna del Estado, evocando una nueva autonomía popular proveniente de la identidad étnica. La confrontación de las identidades nacionales-estatales con las étnicas se forma en una intensa negociación global sobre los destinos de la soberanía local que pone en entredicho el dominio eminente del Estado sobre la naturaleza y el territorio; aspectos que influyen en la economía de inversión, en las políticas de desarrollo, en el derecho y en la cultura nacional. Envolturas que necesitan ser estudiadas en detalle para comprender el impacto real de dicha diplomacia en temas como los negocios petroleros, las mineras, el ecoturismo y otros más. En breve, la diplomacia indígena es un fenómeno que debe considerarse en diversos aspectos, aún inexplorados, si de verdad nos interesa comprender la formación y desarrollo del sistema mundial. 


\section{Referencias}

Aquila, R. (1997). The iroquois restoration: Iroquois diplomacy on the colonial frontier, 17011754. Londres: Nebraska Press.

Arévalo Robles, G. A. (2011a). La lucha transnacional indígena: Articulaciones transfronterizas para interpelar a la civilización occidental. Conjeturas, 12, 43-56.

Arévalo Robles, G. A. (2011b). Los prismas de la lucha transnacional indígena. Trabajo y Ensayos, 13, 1-20.

Bengoa, J. (2007). La emergencia indígena en América Latina. Santiago: Fondo de Cultura Económica.

Brysk, A. (2009). De la tribu a la aldea global: Derechos de los pueblos indígenas, redes transnacionales y relaciones internacionales en América Latina. Barcelona: Ediciones Bellaterra.

Choque Canqui, R. (2011). Los contenidos ideológicos y políticos del liderazgo aymara en Bolivia (1900-1945). Cuadernos Interculturales, 9 (17), 99-112.

Contreras, C. (2007). Koyang: parlamento y protocolo en la diplomacia mapuche-castellana, siglos XVI-XIX. Nuke Mapu Förlaget/FDCL. Recuperado de FDCL: http://fdclberlin. de/index.php

Contreras, C. (2010). Los tratados celebrados por los Mapuche con la Corona Española, la República de Chile y la República de Argentina (tesis doctoral). Freie Universität Berlin, Berlin.

Cornago, N. (2013). Plural diplomacies: Normative predicaments and functional imperatives. Boston: Martinus Nijhoff Publishers.

Corntassel, J. (2007). Towards a new partnership? Indigenous political mobilization and cooptation during the first UN indigenous decade (1995-2004). Human Rights Quarterly, 29 (1), 137-166.

Costa, R. (2006). A higher authority: Indigenous transnationalism and Australia. Sídney: UNSW Press.

166 Si Somos Americanos. Revista de Estudios Transfronterizos 
Crespo Flores, C. (2005). La negociación como dispositivo para reducir relaciones de dominación: aspectos conceptuales y metodológicos. En H. Darío Correa y I. Rodríguez (ed.), Encrucijadas ambientales en América Latina. Entre el manejo y la transformación de conflictos por recursos naturales (pp. 237-255). Costa Rica: Universidad para la Paz.

Dahl, J. (2009). IWGIA: A history. Copenhagen: IWGIA.

De Sousa Santos, B. (2009). Sociología jurídica crítica: Para un nuevo sentido común en el derecho. Bogotá: ILSA.

Escuela Diplomática Plurinacional. (2009a). Aprendiendo nuevos protocolos: El akhulli, la hoja de coca en la diplomacia de los pueblos. La Paz: Ministerio de Relaciones Internacionales.

Escuela Diplomática Plurinacional. (2009b). Aprendiendo nuevos protocolos: El apthapi. El banquete indígena en la diplomacia de los pueblos. La Paz: Ministerio de Relaciones Internacionales.

Favre, H. (1998). El indigenismo. México: Fondo de Cultura Económica.

Foley, G., Schaap, A. y Howell, E. (2013). The aboriginal tent embassy: Sovereignty, black power, land rights and the state. Londres: Routledge.

García, C. (1999). Interacción étnica y diplomacia de fronteras en el reino Miskitu a fines del siglo XVIII. Anuario de Estudios Americanos, 56 (1), 95-121.

Havard, G. (2001). The great peace of Montreal of 1701: French-native diplomacy in the seventeenth century. Londres: MQUP.

Huanacuni Mamani, F. (2012). Cosmovisión Andina, Parte 1. Vivir Bien/Buen Vivir. En F. Huanacuni Mamani (ed.), Conjunto de visiones sobre la Postmodernidad (Ciclo de Conferencias). La Paz: Publicaciones Casa de la Libertad.

Jennings, F. y Fenton, W. N. (1995). The history and culture of iroquois diplomacy: An interdisciplinary guide to the treaties of the six nations and their league. Nueva York: Syracuse University Press.

Johnson, M. (2003). Tribes of the iroquois confederacy. Oxford: Osprey Publishing. 
Keck, M. y Sikkink, K. (2000). Activistas sin fronteras: Redes de defensa en política internacional. México: Siglo XXI Editores.

Langton, M. (2004). Honour among nations: Treaties and agreements with indigenous people. Melbourne: Melbourne University Press.

Lázaro Ávila, C. (1999). Conquista, control y convicción: el papel de los parlamentos indígenas en México, el Chaco y Norteamérica. Revista de Indias, 59 (217), 645-673.

Levaggi, A. (2002) Diplomacia hispano-indígena en las fronteras de América: Historia de los tratados entre la monarquía española y las comunidades aborígenes. Madrid: Centro de Estudios Políticos y Constitucionales.

López Sarrelangue, D. E. (1965). La nobleza indígena de Pátzcuaro en la época virreinal. México: Universidad Nacional Autónoma de México.

Midtrød, T. A. (2012). The memory of all ancient customs: Native American diplomacy in the colonial Hudson Valley. Nueva York: Cornell University Press.

Morgenthau, H. (1986). Política entre las naciones. Buenos Aires: Grupo Editor Latinoamericano.

Ochoa Arias, M., Hutchinson, J. y Arias Arias, L. F. (2012). Tejiendo alianzas para la diplomacia indígena: Ejercicios de la experiencia de la Organización Nacional Indígena de Colombia, ONIC 2006-2012. Bogotá: ONIC.

Panikkar, R. (1994). El Cristo desconocido del hinduismo para una cristofanía ecuménica. Madrid: Grupo Libro 88.

Reinaga, F. (1971). Tesis india. La Paz: Ediciones PIB.

Ríos Montero, H. (2002). Los ayllus de Tacobamba: Procesos históricos, desarrollo y poder local. La Paz: Fundación PIEB.

Ruiz Medrano, E., Barrera Gutiérrez, C. y Barrera Gutiérrez, F. (2013). La lucha por la tierra: Los títulos primordiales y los pueblos indios en México, siglos XIX y XX. México: Fondo de Cultura Económica. 
Sanders, D. (1977). The Formation of the World Council of Indigenous Peoples (Document 29). Copenhage: IWGIA.

Sanjeev, K., Riker, J. V. y Sikkink, K. (2002). Restructuring world politics: Transnational social movements, networks, and norms. Minneapolis: University of Minnesota Press.

Stavenhagen, R. (1998). Las organizaciones indígenas: actores emergentes de América Latina. En L. González Volio (ed.), Presente y futuro de los derechos humanos. Ensayos en honor a Fernando Volio Jiménez. San José: Instituto Interamericano de Derechos Humanos.

Torres, G. A. (2013). Diplomacia indígena: transitando del problema a la solución. Revista Mexicana de Política Exterior, (98), 197-232.

Yarrow, D. (1987). The great law of peace: New world roots of american democracy, turtle eyeland, the unity of biology and ecology with spirit. http://www.kahonwes.com/ iroquois/document1.html 